\title{
Analysis and Implementation of Thermal Heat Exchanger Tube Performance with Helically Pierced Twisted Tape Inserts Using ANFIS Model
}

\author{
Faisal Altarazi, ${ }^{1}$ Sunil Kumar $\left(\mathbb{D},{ }^{2}\right.$ Gaurav Gupta $\left(\mathbb{D},{ }^{2}\right.$ Muhammad Gulzar $\mathbb{D}^{3},{ }^{3}$ \\ Yaé Ulrich Gaba $\oplus^{4},{ }^{4}$ Anil Kumar, ${ }^{5}$ and Rajesh Maithani $\mathbb{D}^{5}$ \\ ${ }^{1}$ Applied College, University of Jeddah, Jeddah, Saudi Arabia \\ ${ }^{2}$ Yogananda School of Artificial Intelligence Computers and Data Science, Shoolini University, Solan, India \\ ${ }^{3}$ Department of Mathematics, Government College University Faisalabad, Faisalabad 38000, Pakistan \\ ${ }^{4}$ Quantum Leap Africa(QLA) AIMS Rwanda Centre, Remera Sector KN 3, Kigali, Rwanda \\ ${ }^{5}$ School of Engineering, University of Petroleum and Energy Studies, Dehradun, India \\ Correspondence should be addressed to Sunil Kumar; reachtome.sunil@gmail.com and Yaé Ulrich Gaba; \\ yaeulrich.gaba@gmail.com
}

Received 13 August 2021; Accepted 17 November 2021; Published 20 December 2021

Academic Editor: Debiao Meng

Copyright (C) 2021 Faisal Altarazi et al. This is an open access article distributed under the Creative Commons Attribution License, which permits unrestricted use, distribution, and reproduction in any medium, provided the original work is properly cited.

\begin{abstract}
The present work used ANFIS, an adaptive neuro-fuzzy inference system modeling to analyze the effect of the variable parameters of helically pierced twisted tape inserts on the Nusselt number, friction factor, and thermo-hydraulic heat exchanger tube performance. The experimental data utilized for ANFIS modeling considered a diameter ratio ranging from 0.57 to 0.80 , a relative pitch ratio ranging from 0.046 to 0.107 , a perforation index ranging from $5 \%$ to $20 \%$ as variable twisted tape parameters and flow parameters. The Reynolds number varies from 4000 to 30000 . The analysis showed that the maximum thermo-hydraulic performance was obtained at a diameter ratio of 0.65 , a relative pitch ratio of 0.085 , and a perforation index equal to $10 \%$. The result predicts that the ANFIS model and experimental results are in good agreement as they have only $\pm 0.53 \%$ deviations.
\end{abstract}

\section{Introduction}

Heat exchangers are broadly utilized in designing applications, for example, refrigeration and cooling systems, automobiles, thermal power plants, textile and chemical handling industries, and so forth. The efficiency of the heat exchanger is decided on the basis of the effective heat transfer between two working fluids [1, 2]. Numerous methods and approaches were instigated for the augmentation of heat transfer to improve thermal efficiency. The ultimate aim of these approaches is to increase the heat transfer and provide the stability of the heat exchanger [3-6].

Rounded tubes are prominently used in most engineering industries because of their compact structure for a given available space [7, 8]. Nakhchi and Esfahani [9] studied experimentally the thermal performance of a heat exchanger tube fortified with cross-cut twisted tape using
$\mathrm{Cu}-\mathrm{H}_{2} \mathrm{O}$ nanofluid. The outcomes showed that the thermal performance of $\mathrm{Cu}-\mathrm{H}_{2} \mathrm{O}$ nanofluid flow in the plain tube is lesser than the tubes equipped with the cross-cut twisted tapes. Xiaowen et al. [10] performed experimental studies on a domestic water-cooled air conditioner (WAC) and reported that the COP of WAC increases to $12.3 \%$ with the insertion of the heat recovery option. Ishak et al. [11] evaluated the Nusselts number $(\mathrm{Nu})$ for the bundles of the flat tube and found that $N u$ increases, whereas the friction factor decreases, with an escalation in the mean air velocity. Fullerton and Anand [12] and Jang and Yang [13-16] analyzed the heat transfer enhancement techniques on the heat exchangers.

Modern investigations are more focused on soft computing fields and computational intelligence. Computational intelligence includes computational fluid dynamic (CFD), artificial neural networks (ANN), fuzzy inference system 
(FIS), genetic algorithm (GA), particle swarm optimization (PSO), and fuzzy logic [17]. The fuzzy sets play important role in artificial neural network [18] and inference system [19]. The fuzzy models can be pooled with ANN to produce ANFIS. The modeling of a nonlinear system is now quite easier with ANFIS as ANFIS has the benefits of neural and fuzzy logic systems [20, 21]. Kiran and Rajput [22] determined that soft computing tools, such as FIS, ANN, and ANFIS, provide a modest but influential technique for predicting the performance of a heat exchanger.

Suparta and Samah [23] predicted rainfall by exploring the application of the ANFIS model with various input structures and membership functions. The analyses of sixyear rainfall data on a monthly basis in South Tangerang city, Indonesia found that the rainfall prediction based on the ANFIS time series is promising, where $80 \%$ of the data testing is well-predicted. Elijah Onu et al. [24] carried the comparative analysis of RSM, ANN, ANFIS, and mechanistic modeling in the Eriochrome black-T (EBT) dye adsorption using modified clay. They found that ANFIS is the best predictive model, whereas RSM is the least in the adsorption of EBT dye. Mehrabi et al. [25] and Esen et al. [26] used ANFIS, whereas Beigzadeh and Rahimi [27, 28] used ANFIS and GA for modeling the influence of the essential parameters of the heat exchangers. Esen and Inalli [29], Hayati et al. [30], and Esen et al. [31] predicted $N u$ using novel geometry in a heat exchanger using ANFIS.

Chen et al. [32] and Mohammad [33] studied experimentally the $N u$ and $f$ in a double tube heat exchanger using ANN. The $99.76 \%$ and $99.54 \%$ of data regression coefficients for $N u$ and $f$, respectively, illustrated the accurateness of the method applied. Gill and Singh [34], Zarei et al. [35], and Abadi et al. [36] adopted the ANFIS approach for predicting the energetic performance analysis and found that the ANFIS predictions agreed well with the experimental results with an absolute fraction of variance in the range of 0.994-0.998, a root mean square error in the range of $0.0018-0.1907$, and a mean absolute percentage error in the range of $0.103-0.897 \%$. Onyelowe et al. [37] implemented ANFIS and its evolutionary hybrid techniques, ANFIS-PSO and ANFIS-GA, to forecast the coefficients of curvature and the uniformity of unsaturated lateritic soil and concluded that ANFIS and its evolutionary hybrids techniques showed great accuracy. Marjani et al. [38] used the application of ANFIS to obtain the results of CFD modeling to facilitate the prediction of the pressure of the nanofluid convective flow. The ANFIS predictions show a good agreement with the CFD results. Saee et al. [39], Beiki [40], Bahiraei et al. [41], Yashawantha and Vinod [42], Bahl et al. [43], Safarzadeh et al. [44], and Safarzadeh et al. [44] used the ANFIS model for different heat transfer enhancement applications, and their major findings are listed in Table 1.

From the literature review, it can be concluded that ANFIS is a better modeling system as it is an amalgamation of ANN combined with FIS to improve the speed, adaptiveness, and fault tolerance. It can assimilate the linguistic variables that are a part of human language, reasoning, and understanding [46-48]. The use of modern and advanced techniques leads to the saving of time, energy, and material by analyzing them on the basis of the performance dominance parameter [49]. Furthermore, the literature review shows so many studies on predicting the performance of the heat exchanger. However, very limited research has been found on the passive methods with helically pierced twisted tape inserts using ANFIS. In the present study, ANFIS modeling is used to predict $N u_{T T}$ and $f_{T T}$ of the heat exchanger tube. It is also used to determine the geometrical parameter values by finding out their dominance and involvement in the performance assessment. The novelty of the present work is the prediction of the geometric parameter that delivers the maximum heat transfer inside a heat exchanger tube. The ANFIS method determines the dominating parameter on the basis of thermal performance to lower the experimental runs and saves time and money. The determined bestsuited parameters can be used in a heat exchanger tube to enhance the heat transfer with the lowest possible pressure drop penalty.

\section{Range of Parameters}

The variable geometrical parameters of the helical pierced twisted-tape inserts and the corresponding range taken for the investigations [50] are as follows: diameter ratio $\left(d_{R} / D_{I}\right)$ ranging from 0.57 to 0.80 , relative pitch ratio $\left(P_{P T} / L_{T}\right)$ ranging from 0.046 to 0.107 , perforation Index $\left(P_{A} / T_{A}\right)$ ranging from $5 \%$ to $20 \%$, and Reynolds number $\left(\mathrm{Re}_{\text {num }}\right)$ ranging from 4000 to 30000 . For the graphic representation of the helical pierced twisted tape inserts, see Figure 1.

\section{Experimental Setup Details}

The heat exchanger tube is made of galvanized iron with outer and inner diameters of $68 \mathrm{~mm}$ and $65 \mathrm{~mm}$, respectively. The heat exchanger tube has three sections, viz., the inlet, outlet, and test section, which are of of $2.5 \mathrm{~m}, 1.5 \mathrm{~m}$, and $1.4 \mathrm{~m}$, respectively, as shown in Figure 2 [50]. The fluid flow across the tube is carried by a centrifugal blower. A tailored Nicrome wire heater is employed to maintain a $1000 \mathrm{~W} / \mathrm{m}^{2}$ constant heat flux in the test section. The pressure drop across the test section is determined by a digital micromanometer (TESTO-510) with a least count of $1 \mathrm{~Pa}$. The temperature is determined by 12 thermocouples attached on the test section, 3 thermocouples at the outlet, and 1 thermocouple at the inlet section [50]. The thermocouples have been calibrated in laboratory conditions against a dry block temperature calibrated instant (Presys Instruments $\mathrm{T}-25 \mathrm{~N}, 2004)$, having the least count of $0.01^{\circ} \mathrm{C}$. The thermocouple to be calibrated was placed in the calibration bath where a constant temperature was maintained. The response of the thermocouple and the standard probe were noted with the help of a digital temperature indicator for various preset values of the standard probe, and the error between the reading of the standard probe and the thermocouple were calculated. 
TABle 1: Previous investigations on ANFIS modeling.

\begin{tabular}{|c|c|c|}
\hline $\begin{array}{l}\text { S. } \\
\text { No. }\end{array}$ & Authors & Major findings \\
\hline 1. & Saee et al. [39] & $\begin{array}{c}\text { ANFIS model is an easy-to-use tool to estimate nucleate pool boiling heat transfer properties of } \\
\text { refrigerant-oil mixtures with nanoparticles. }\end{array}$ \\
\hline 2. & Beiki [40] & $\begin{array}{l}\text { FIS and ANFIS are a most powerful weapon to attack mass transfer in nanofluids. Also these models } \\
\text { could predict convective mass transfer in nanofluids very effectively. } \\
\text { Nanoparticles size and type could play an important role in mass transfer. }\end{array}$ \\
\hline 3. & Bahiraei et al. [41] & $\begin{array}{l}\text { PSO-ANFIS acts as most capable predictive model, followed by PSO-ANN, ANFIS, and ANN. } \\
\text { ANFIS and ANN can be optimized by PSO approach. }\end{array}$ \\
\hline 4. & $\begin{array}{l}\text { Yashawantha and Vinod } \\
\qquad[42]\end{array}$ & $\begin{array}{l}\text { Correlation and ANFIS model were developed for effective thermal conductivity. } \\
\text { ANFIS model showed better performance compared to correlation. }\end{array}$ \\
\hline 5. & Bahl et al. [43] & $\begin{array}{l}\text { The predictions obtained by using the ANFIS model are found to be very close to the experimental } \\
\text { findings which prove that the model proposed is capable to accurately predict the behavior of heat } \\
\text { transfer system. }\end{array}$ \\
\hline 6. & Safarzadeh et al. [44] & $\begin{array}{l}\text { The AFNIS model predicted the results with relative and average relative errors of } 1.76 \% \text { and } 0.67 \% \text { for } \\
\text { nusselt number, } 11.34 \% \text { and } 4.48 \% \text { for friction factor, and } 8.56 \% \text { and } 2.83 \% \text { for entropy generation. } \\
\text { ANN and ANFIS models can be used confidently to estimate the exergy efficiency. }\end{array}$ \\
\hline 7. & Kaveh et al. [45] & $\begin{array}{c}\text { The ANFIS model had more capability to predict the energy and exergy items as compared to ANN } \\
\text { method. }\end{array}$ \\
\hline
\end{tabular}

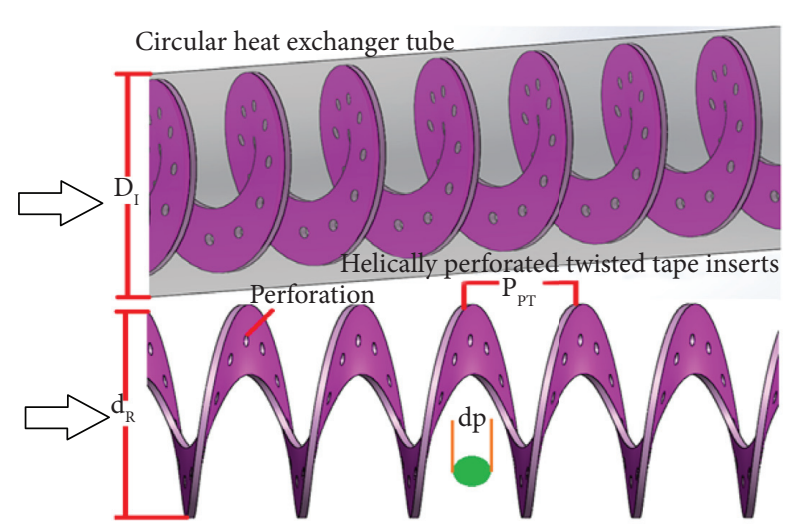

Figure 1: Twisted tape insert parameters [50].

\section{ANFIS Model}

ANFIS is an adaptive network that utilizes the features of ANN and fuzzy logic. ANFIS implicitly executes these two approaches. In this study, Takagi-Sugeno fuzzy inference system with a five-layered structure is employed. The structure of the proposed model (ANFIS) is represented in Figure 3 [42], whereas the plotted membership function of the input and output parameters are demonstrated by Figure 4. To regulate the output parameters in the model, the structured rules are given in Table 2.

For effortlessness, we use two inputs $X$ and $Y$ and corresponding one output FF. Two criteria were used in the approach of "if-Then" for Takagi-Sugeno model, as follows:

Criteria $1=$ If $X$ is $A_{1}$ and $Y$ is $B_{1}$,

$$
f_{1}=P_{1} X+Q_{1} Y+R_{1} \text {. }
$$

Criteria $2=$ If $X$ is $A_{2}$ and $Y$ is $B_{2}$,

$$
f_{2}=P_{2} X+Q_{2} Y+R_{2}
$$

where $A_{1}$ and $A_{2}$ are the membership functions for input $X$. Similarly, $B_{1}$ and $B_{2}$ are the membership functions for input Y. $P_{1}, Q_{1}, R_{1}, P_{2}, Q_{2}$, and $R_{2}$ are the linear parameters of Takagi-Sugeno fuzzy inference model.

ANFIS model comprises of five layers, and the brief narrative of all these is as follows [21]:

Layer 1: Each node of this layer acclimates with a parameter function and output of each node is a degree of membership, which is given by the input of the membership functions.

$$
\begin{aligned}
Z_{A i}(X) & =\frac{1}{1+\left|\left(X-c_{i} / a_{i}\right)\right|^{2 b}}, \\
L_{1 i} & =Z_{A i}(X), \quad i=1,2, \\
L_{1 i} & =Z_{B i}(Y), \quad i=1,2,
\end{aligned}
$$

where $Z_{A i}(X)$ and $Z_{B i}(Y)$ are the degree of the membership functions of fuzzy sets $A_{i}$ and $B_{i}$, respectively, whereas $a_{i}, b_{i}, c_{i}$ are the parameters of the membership function.

Layer 2: In this layer, each node is nonadaptive and categorized as $E$. The output node is the outcome of the multiplication of signal coming into the node and carried out to the next node. The outputs of these nodes are given as follows:

$$
L_{2 i}=W_{i}=Z_{A i}(X) * Z_{B i}(Y), \quad i=1,2,
$$

where output $W_{i}$ represents the firing strength of each rule.

Layer 3: Each node in the third layer is categorized as $\mathrm{N}$. Every node is a calculation of the ratio between the $i^{\text {th }}$ rule and the sum of all rules. 


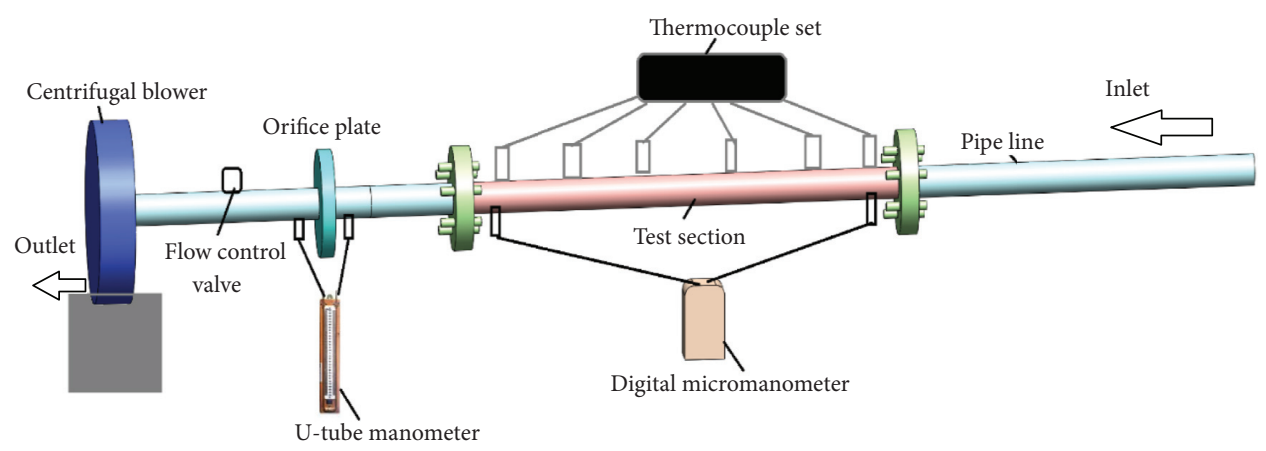

(a)

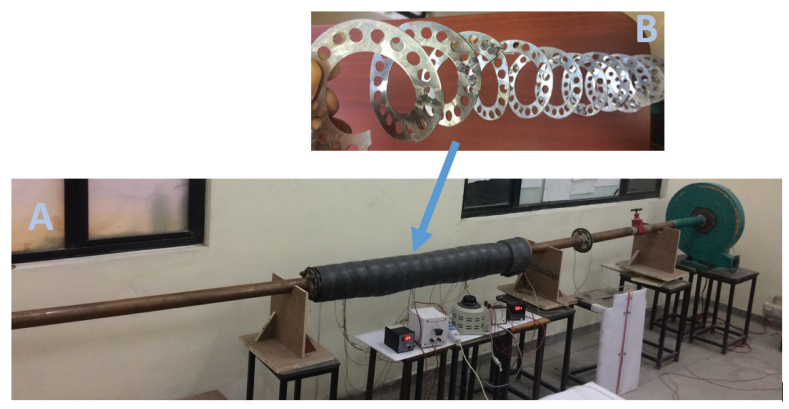

(b)

Figure 2: (a) Schematic of experimental setup. (b) Photographic view of experimental setup and insert.

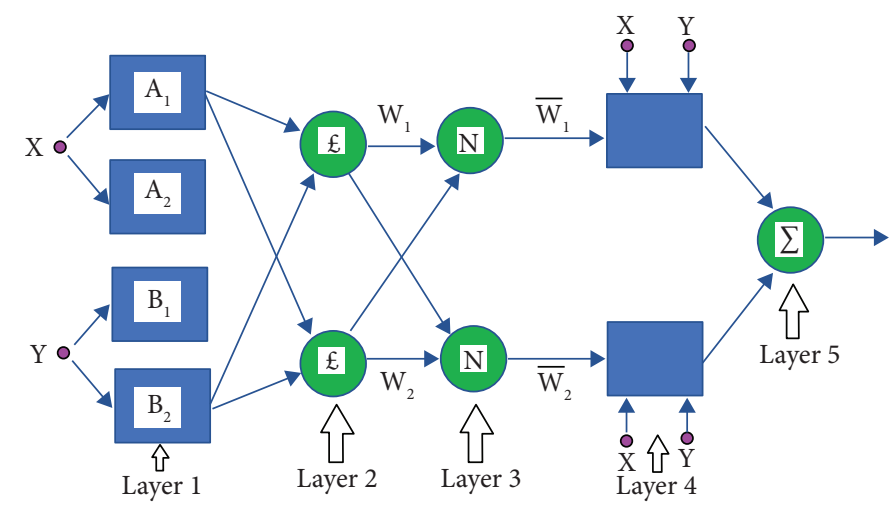

Figure 3: Schematic ANFIS model [17].

$$
L_{3 i}=\underline{W}_{i}=\frac{W_{i}}{W_{1}+W_{2}}, \quad i=1,2 .
$$

Layer 4: Every node in layer four is an adaptive node to an output that is defined as [21] follows:

$$
L_{4 i}=\underline{W}_{i} f_{i}=\underline{W}_{i}\left(P_{i} X+Q_{i} Y+R_{i}\right), \quad i=1,2 .
$$

Layer 5: The single node of layer five is labeled as $\Sigma$, which calculates the whole output of all received signals of the earlier nodes.

$$
L_{5 i}=\sum_{i=1}^{2} \underline{W}_{i} f_{i}=\frac{\sum_{i=1}^{2} W_{i} f_{i}}{W_{1}+W_{2}} .
$$

\section{Data Reduction}

From the experimental data recorded for the heat exchanger under the steady state conditions, $N u_{T T}, N u_{T T}, f_{T T}$, and $\eta_{\text {per }}$ were computed as follows $[50,51]$ :

$f_{T T}$ across the test section is calculated using the Darcy equation as follows $[50,51]$ :

$$
f_{T T}=\frac{2(\Delta P)_{d} \cdot D}{4 \cdot \rho \cdot L \cdot V^{2}},
$$

where $(\Delta \mathrm{P})_{\mathrm{d}}=9.81 \times(\Delta \mathrm{h})_{\mathrm{d}} \times \rho_{\mathrm{m}}$.

$N u_{T T}$ is determined from the followingequation:

$$
N u_{T T}=\frac{h \cdot D}{k},
$$



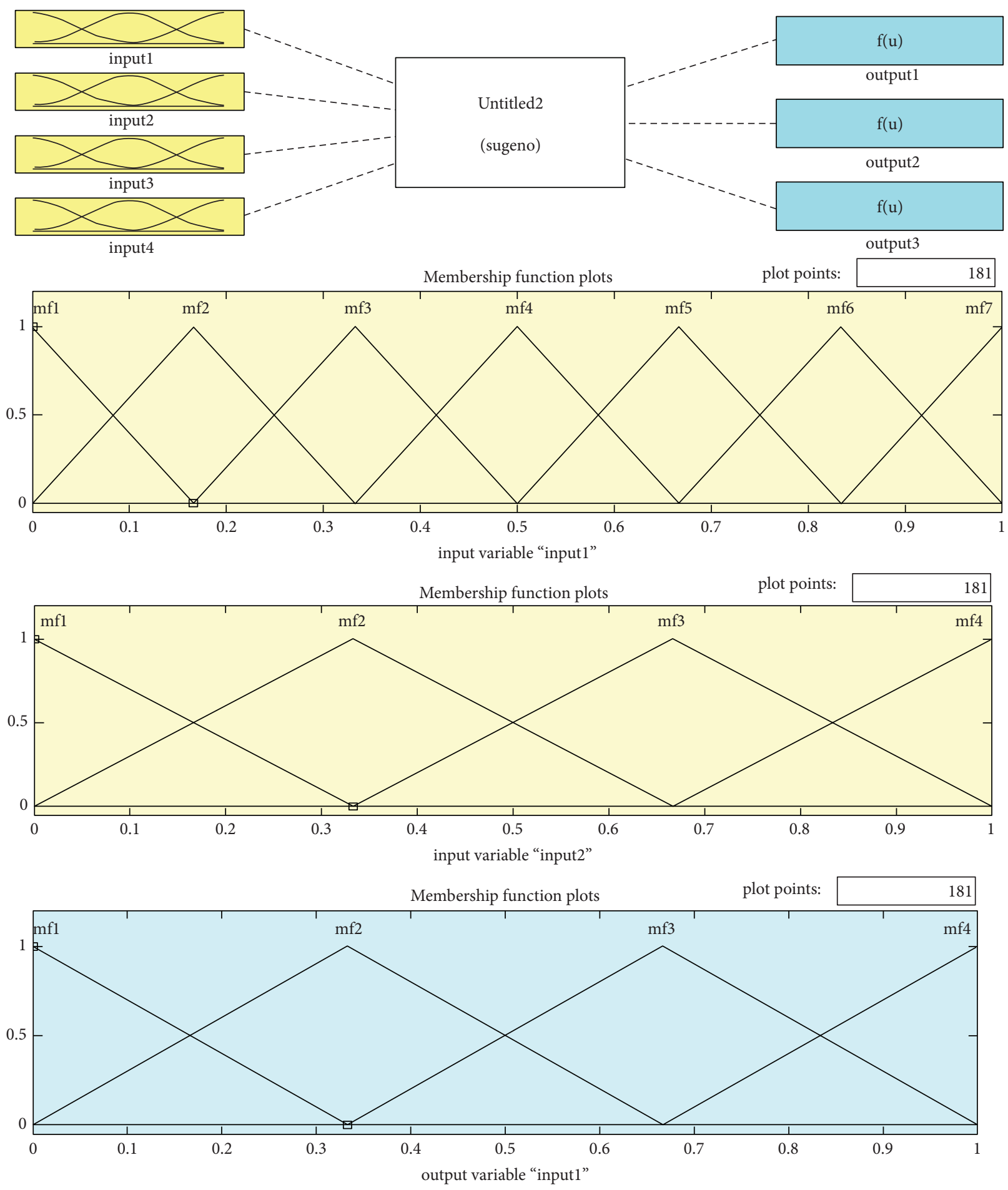

FIGURE 4: Membership function plot for input and output variables.

where,

$$
h=\frac{Q_{u}}{A_{T} \cdot\left(T_{t m}-T_{f m}\right)} .
$$

The useful heat transfer rate $Q_{u}$ of the fluid is given by,

$$
Q_{u}=\dot{m} \times C_{p, n f}\left(T_{0}-T_{i}\right)
$$

The heat exchanger with the pierced twisted tape inserts thermal performance compared to a smooth tube is obtained as follows [50, 51]:

$$
\eta_{\text {per }}=\frac{\left[\left(N u_{T T} / N u_{\text {smooth }}\right)\right]}{\left[\left(f_{T T} / f_{\text {smooth }}\right)\right]^{(1 / 3)}} .
$$


TABLE 2: ANFIS input and output rule for modeling pierced twisted tape inserts heat exchanger.

\begin{tabular}{|c|c|}
\hline S. no. & Rules \\
\hline 1 & If (input 1 is in $1 \mathrm{mf} 1$ ) and (input2 is in $2 \mathrm{mf} 1$ ) then (output is $1 \mathrm{mf} 1$ ) (1) \\
\hline 2 & If (input 1 is in $1 \mathrm{mf} 1$ ) and (input 2 is in $2 \mathrm{mf} 2$ ) then (output is $1 \mathrm{mf} 2$ ) (1) \\
\hline 3 & If (input 1 is in $1 \mathrm{mf} 1$ ) and (input2 is in $2 \mathrm{mf} 3$ ) then (output is $1 \mathrm{mf} 3$ ) (1) \\
\hline 4 & If (input 1 is in $1 \mathrm{mf} 1$ ) and (input 2 is in $2 \mathrm{mf} 4$ ) then (output is $1 \mathrm{mf} 4$ ) (1) \\
\hline 5 & If (input 1 is in $1 \mathrm{mf} 2$ ) and (input 2 is in $2 \mathrm{mf} 1$ ) then (output is $1 \mathrm{mf} 5$ ) (1) \\
\hline 6 & If (input 1 is in $1 \mathrm{mf} 2$ ) and (input 2 is in $2 \mathrm{mf} 2$ ) then (output is $1 \mathrm{mf6}$ ) (1) \\
\hline 7 & If (input 1 is in $1 \mathrm{mf} 2$ ) and (input2 is in $2 \mathrm{mf} 3$ ) then (output is $1 \mathrm{mf} 7$ ) (1) \\
\hline 8 & If (input 1 is in $1 \mathrm{mf} 2$ ) and (input 2 is in $2 \mathrm{mf} 4$ ) then (output is $1 \mathrm{mf} 8$ ) (1) \\
\hline 9 & If (input 1 is in $1 \mathrm{mf} 3$ ) and (input2 is in $2 \mathrm{mf} 1$ ) then (output is $1 \mathrm{mfg}$ ) (1) \\
\hline 10 & If (input 1 is in $1 \mathrm{mf} 3$ ) and (input 2 is in $2 \mathrm{mf} 2$ ) then (output is $1 \mathrm{mf} 10$ ) (1) \\
\hline 11 & If (input 1 is in $1 \mathrm{mf} 3$ ) and (input 2 is in $2 \mathrm{mf} 3$ ) then (output is $1 \mathrm{mf} 11$ ) (1) \\
\hline 12 & If (input 1 is in $1 \mathrm{mf} 3$ ) and (input 2 is in $2 \mathrm{mf} 4$ ) then (output is $1 \mathrm{mf} 12$ ) (1) \\
\hline 13 & If (input 1 is in $1 \mathrm{mf} 4$ ) and (input 2 is in $2 \mathrm{mf} 1$ ) then (output is $1 \mathrm{mf} 13$ ) (1) \\
\hline 14 & If (input 1 is in $1 \mathrm{mf} 4$ ) and (input 2 is in $2 \mathrm{mf} 2$ ) then (output is $1 \mathrm{mf} 14$ ) (1) \\
\hline 15 & If (input 1 is in $1 \mathrm{mf} 4$ ) and (input 2 is in $2 \mathrm{mf} 3$ ) then (output is $1 \mathrm{mf} 15$ ) (1) \\
\hline 16 & If (input 1 is in $1 \mathrm{mf} 4$ ) and (input 2 is in $2 \mathrm{mf} 4$ ) then (output is $1 \mathrm{mf} 16$ ) (1) \\
\hline 17 & If (input 1 is in $1 \mathrm{mf} 5$ ) and (input 2 is in $2 \mathrm{mfl}$ ) then (output is $1 \mathrm{mf} 17$ ) (1) \\
\hline 18 & If (input 1 is in $1 \mathrm{mf} 5$ ) and (input 2 is in $2 \mathrm{mf} 2$ ) then (output is $1 \mathrm{mf} 18$ ) (1) \\
\hline 19 & If (input 1 is in $1 \mathrm{mf} 5$ ) and (input 2 is in $2 \mathrm{mf} 3$ ) then (output is $1 \mathrm{mf} 19$ ) (1) \\
\hline 20 & If (input 1 is in $1 \mathrm{mf} 5$ ) and (input 2 is in $2 \mathrm{mf} 4$ ) then (output is $1 \mathrm{mf} 20$ ) (1) \\
\hline 21 & If (input 1 is in $1 \mathrm{mf} 6$ ) and (input 2 is in $2 \mathrm{mf} 1$ ) then (output is $1 \mathrm{mf} 21$ ) (1) \\
\hline 22 & If (input 1 is in $1 \mathrm{mf} 6$ ) and (input 2 is in $2 \mathrm{mf} 2$ ) then (output is $1 \mathrm{mf} 22$ ) (1) \\
\hline 23 & If (input 1 is in $1 \mathrm{mf} 6$ ) and (input 2 is in $2 \mathrm{mf} 3$ ) then (output is $1 \mathrm{mf} 23$ ) (1) \\
\hline 24 & If (input 1 is in $1 \mathrm{mf} 6$ ) and (input 2 is in $2 \mathrm{mf} 4$ ) then (output is $1 \mathrm{mf} 24$ ) (1) \\
\hline 25 & If (input 1 is in $1 \mathrm{mf} 7$ ) and (input 2 is in $2 \mathrm{mf} 1$ ) then (output is $1 \mathrm{mf} 25$ ) (1) \\
\hline 26 & If (input 1 is in $1 \mathrm{mf} 7$ ) and (input 2 is in $2 \mathrm{mf} 2$ ) then (output is $1 \mathrm{mf} 26$ ) (1) \\
\hline 27 & If (input 1 is in $1 \mathrm{mf} 7$ ) and (input 2 is in $2 \mathrm{mf} 3$ ) then (output is $1 \mathrm{mf} 27$ ) (1) \\
\hline 28 & If (input 1 is in $1 \mathrm{mf} 7$ ) and (input2 is in $2 \mathrm{mf} 4$ ) then (output is $1 \mathrm{mf} 28$ ) (1) \\
\hline
\end{tabular}

\section{Uncertainties Analysis}

The uncertainty calculation majorly relies on the errors linked to the measuring instruments [50]. The uncertainty evaluation is performed on a single test run with a single set of geometric parameters. The uncertainty results are presented in Table 3 [50].

\section{Validation of Experimental Results}

The smooth tube experimental data for $N u_{\text {smooth }}$ was validated with the Dittus-Boelter equation (13), and $f_{\text {smooth }}$ by the Blasius equation (14) $[25,35,47,50,51]$.

$$
\begin{aligned}
N u_{\text {smooth }} & =0.023 \operatorname{Re}_{\text {num }}^{0.8} \operatorname{Pr}^{0.4}, \\
f_{\text {smooth }} & =0.085 \operatorname{Re}_{\text {num }^{-.}}^{0.25}
\end{aligned}
$$

The comparative data of the experimental and standard correlations for $N u_{\text {smooth }}$ and $f_{\text {smooth }}$ are displayed in Figure 5 , respectively. An equitably validation data is seen that ensures the accuracy of the data collected in the experimentation [50].

\section{Results and Discussion}

The experimental [50] and ANFIS values of the Nusselt number $\left(N u_{T T}\right)$ with the Reynolds number $\left(\operatorname{Re}_{\text {num }} \mathrm{Re}_{\text {num }}\right)$ for a selected diameter ratio $\left(d_{R} / D_{I}\right)$ range with other parameter values, such as $\left(P_{P T} / L_{T}\right)=0.086$ and
$\left(P_{A} / T_{A}\right)=10 \%$, being fixed are represented in Figure 6(a). A continuous increase in $N u_{T T}$ is observed by for incremental $\mathrm{Re}_{\text {num }}$ range. Both experimental and ANFIS results showed that $N u_{T T}$ increases with an increase in $\left(d_{R} / D_{I}\right)$ from 0.57 to 0.65 . However, with a further increase in the value of $\left(d_{R} / D_{I}\right), N u_{T T}$ starts to decrease. The maximum and minimum values of $N u_{T T}$ are achieved for the diameter ratio of 0.65 and 0.80 , respectively. $N u_{T T}$ with the diameter ratio of 0.65 helically pierced twisted tape is higher by approximately $27.11 \%$ than the diameter ratio of 0.80 helically pierced twisted tape that provides a low heat transfer rate. The helical ring diameter is the reason for the heat transfer increment. The turbulence is enhanced by an increase in the diameter that breaks the boundary layer leading to heat transfer enhancement. Any further increase in the diameter beyond a certain limit tends to decrease the rate of heat transfer because of less attachment and detachment locations on the heated tube.

Figure 6(b) displays the experimental and ANFIS results of variation in $f_{T T}$ with $\mathrm{Re}_{\text {num }}$ at selected $\left(d_{R} / D_{I}\right)$ values, and the other parameters $\left(P_{P T} / L_{T}\right)=0.086$ and $\left(P_{A} / T_{A}\right)=$ $10 \%$ are kept constant. It is noticed that $f_{T T}$ is enhanced by increasing the diameter ratio. The maximum $f_{T T}$ is achieved at $\left(d_{R} / D_{I}\right)$ of 0.80 . The minimum and maximum values of $f_{T T}$ are found for the diameter ratio of 0.57 and 0.80 , respectively. The friction factor with the diameter ratio of 0.80 helically pierced twisted tape is higher by approximately $10.69 \%$ than the diameter ratio of 0.57 helically pierced twisted tape that provides a low pressure drop. The increase 
TABLE 3: Uncertainty range of parameter.

\begin{tabular}{lcc}
\hline Sr. no. & Parameter & Range of error (\%) \\
\hline 1 & Reynolds number & $0.78-1.56$ \\
2 & Nusselt number & $1.09-3.32$ \\
3 & Friction factor & $0.78-1.67$ \\
\hline
\end{tabular}

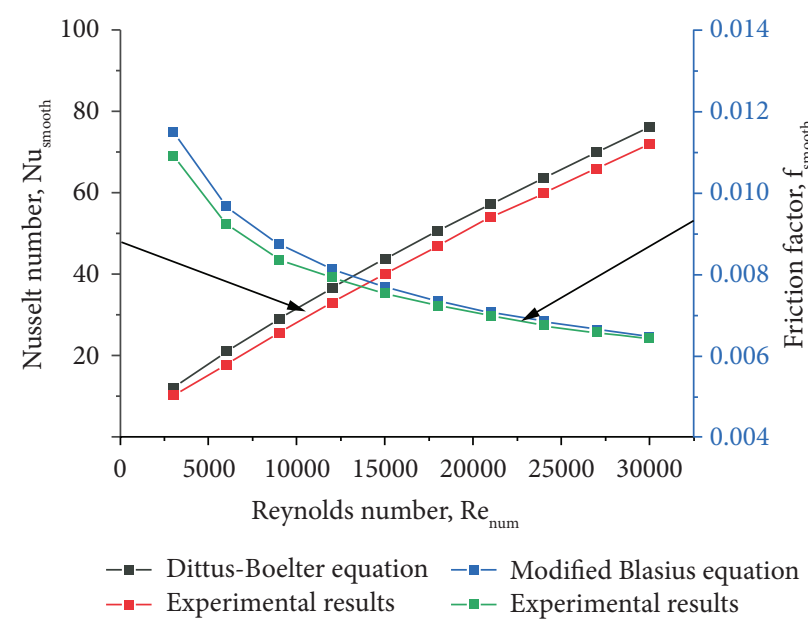

Figure 5: Comparison of experimental data with standard correlations $N u_{\text {smooth }}$ and $f_{\text {smooth }}$.

in the diameter leads to a higher resistance in the path of the fluid flow. This development is detected because an increase in the diameter resists the flow, and higher turbulence is achieved. However, the pressure drop increases, which enhances $f_{T T}$. The main cause behind this disparity is the diameter of the helical ring.

Figure 7(a) illustrates the experimental and ANFIS results on the effect of $\left(P_{P T} / L_{T}\right)$ on $N u_{T T}$ with varying $\mathrm{Re}_{\text {num }}$, keeping other geometrical parameters constant, such as $\left(P_{A} / T_{A}\right)=10 \%$ and $\left(d_{R} / D_{I}\right)=0.65\left(d_{R} / D_{I}\right)=0.65$. It is seen that $N u_{T T}$ is boosted by an increase in $\left(P_{P T} / L_{T}\right)$, and the maximum $N u_{T T}$ is at $\left(P_{P T} / L_{T}\right)$ of 0.086 . A further increase in $\left(P_{P T} / L_{T}\right)$ decreases $N u_{T T}$, and the trend observed is because of a smaller number of attachment and detachment points. The maximum and minimum values of $N u_{T T}$ are found for the pitch ratio of 0.086 and 0.046 , respectively. $N u_{T T}$ with $\left(d_{R} / D_{I}\right)=0.65\left(d_{R} / D_{I}\right)$ of 0.086 helically pierced twisted tape is higher by approximately $10.57 \%$ than $\left(d_{R} / D_{I}\right)=0.65\left(d_{R} / D_{I}\right)$ of 0.046 helically pierced twisted tape that provides a low heat transfer rate. The increases in the twist ratio provides less twists on the test length that generates a lower secondary flow inside the tube. This low number of twists on the tube decreases the heat transferring spots, and hence, the heat transfer rate is reduced.

The experimental and ANFIS values of $f_{T T}$ with $\operatorname{Re}_{\text {num }}$ for a varying range of $\left(P_{P T} / L_{T}\right)$ with other parameter values, such as $\left(P_{A} / T_{A}\right)=10 \%$ and $\left(d_{R} / D_{I}\right)=0.65\left(d_{R} / D_{I}\right)=0.65$ being fixed are represented in Figure $7(\mathrm{~b})$. It is seen that as $\left(P_{P T} / L_{T}\right)$ increases, $f_{T T}$ decreases continuously because of a lower interference offered by a smaller number of helixes on the tape. The highest and lowest values of the friction factor are found for the pitch ratio of 0.046 and 0.107 , respectively.
The friction factor with the pitch ratio of 0.046 helically pierced twisted tape is higher by approximately $24.48 \%$ than the pitch ratio of 0.107 helically pierced twisted tape that provides a low pressure drop. It is because a decrease in $f_{T T}$ in the test section occurs as the $\left(P_{P T} / L_{T}\right)$ value increases, which is because the surface of the tape tends to become parallel to the flow direction.

The experimental and ANFIS results on the effect of $\left(P_{A} / T_{A}\right)$ on $N u_{T T}$ for varying flow $\mathrm{Re}_{\text {num }}$ are represented in Figure $8(\mathrm{a})$. The plot displays an increased $N u_{T T}$ with an increase in $\left(P_{A} / T_{A}\right)$ and produces the maximum $N u_{T T}$ for $\left(P_{A} / T_{A}\right)$ of $10 \%$. The maximum and minimum values of $N u_{T T}$ are found for the perforation index of $10 \%$ and $20 \%$, respectively. $N u_{T T}$ with the perforation index of $10 \%$ helically pierced twisted tape is higher by approximately $9.33 \%$ than the perforation index of $20 \%$ helically pierced twisted tape that provides a low heat transfer. A reduction in $N u_{T T}$ is seen for increasing the value of $\left(P_{A} / T_{A}\right)$ beyond $10 \%$. A reduction in the turbulence intensity inside the tube is observed because of a larger perforation area. At lower perforation, the small dimension diameter delivers in the form of jet, thus producing a high turbulence. A further increase in the $\left(P_{A} / T_{A}\right)$ value beyond $10 \%$ allows the fluid to flow through the larger perforation, and thus, a low-intensity turbulence is produced.

Figure 8(b) illustrates the experimental and ANFIS results on the variation of $\left(P_{A} / T_{A}\right)$ on $f_{T T}$ against the $\mathrm{Re}_{\text {num }}$. A decreasing trend of $f_{T T}$ is observed by boosting up the $\left(P_{A} / T_{A}\right)$ percentage. The higher and the lower values of the hostility factor are found for the perforation index of $5 \%$ and $20 \%$, respectively. The friction factor with the perforation index of $5 \%$ helically pierced twisted tape is higher by approximately $16.17 \%$ than the perforation index of $20 \%$ helically pierced twisted tape that provides a low pressure drop. As $\left(P_{A} / T_{A}\right)$ is leveled up from $5 \%$ to $20 \%, f_{T T}$ goes down, and this consequence occurs because of a large open area available for fluid flow with a lower flow resistance.

The thermal hydraulic performance $\left(\eta_{\text {per }}\right)$ of the heat exchanger incorporated with the helical pierced twisted tape comprises of the simultaneous assessment of $N u_{T T}$ and $f_{T T}$ as related to the smooth tube. Figure 9(a) illustrates the effect of $\left(d_{R} / D_{I}\right)$ on $\eta_{\text {per }}$. It is seen that $\eta_{\text {per }}$ is observed to elevate the value of $\left(d_{R} / D_{I}\right)$ up to 0.65 , and thereafter, any increase in $\left(d_{R} / D_{I}\right)$ reduces $\eta_{\text {per }}$. The higher value of $\eta_{\text {per }}$ is 2.13 .

Figure 9 (b) illustrates the effect of $\left(P_{P T} / L_{T}\right)$ on $\eta_{\text {per }}$, the maximum $\eta_{\text {per }}$ is attained corresponding to $\left(P_{P T} / L_{T}\right)$, and the value is found to be 2.08. $\eta_{\text {per }}$ for $P_{A} / T_{A}$ is represented in Figure 9(c), which illustrated the effect of $P_{A} / T_{A}$ in the range of $5 \%$ to $20 \%$. The maximum $\eta_{\text {per }}$ is found at $P_{A} / T_{A}$ of $10 \%$, and the maximum $\eta_{\text {per }}$ is found to be 2.09 . Thus, the inference is that the optimum value of $\eta_{\text {per }}$ takes place at the values of $\left(d_{R} / D_{I}\right),\left(P_{P T} / L_{T}\right)$, and $P_{A} / T_{A}$ of $0.65,0.8$, and $5 \%$, respectively.

Figures 10(a)-10(c) illustrates the comparison between the experimental and ANFIS-predicted results for $N u_{T T}$, $f_{T T}$, and $\eta_{\text {per }}$. It may be seen that the ANFIS-predicted results and experimental results are in good consideration with each other, which assures the correctness of the information generated. 


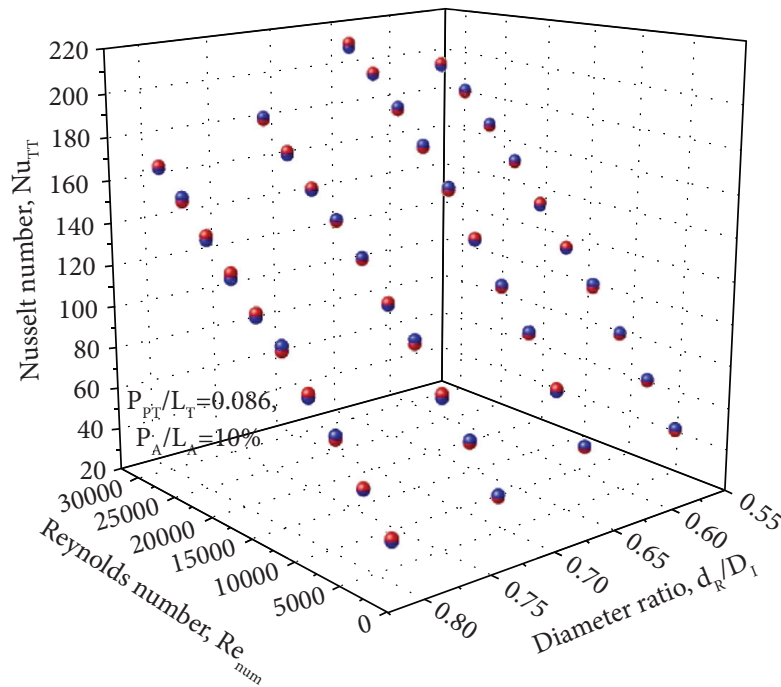

Experimental results ANFIS results

(a)

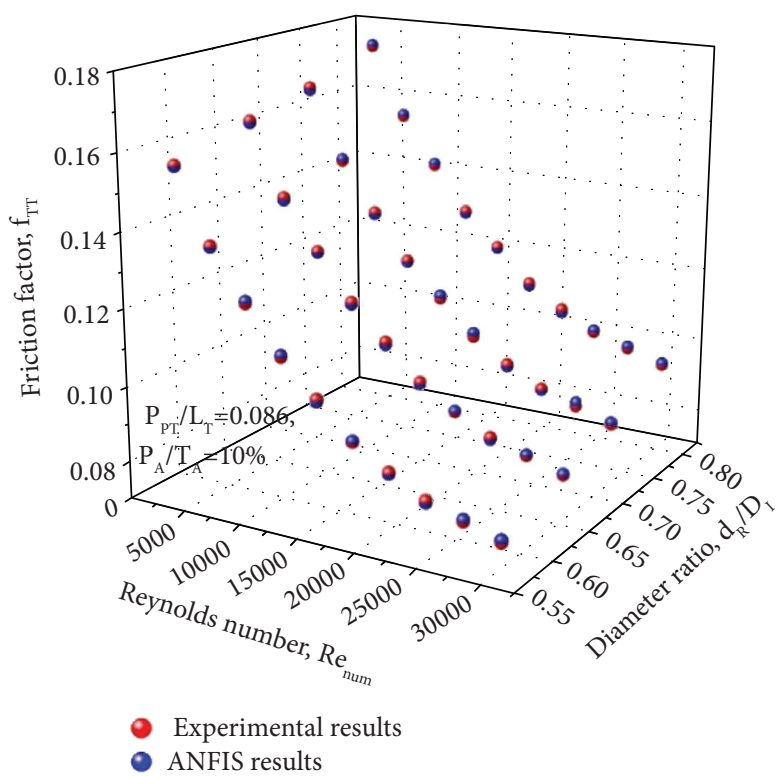

(b)

Figure 6: Experimental and ANFIS results of the variation of (a) $N u_{T T}$ and (b) $f_{T T}$ for various values of $\left(d_{R} / D_{I}\right)=0.65\left(d_{R} / D_{I}\right)$ at different $\operatorname{Re}_{\text {num }}$.

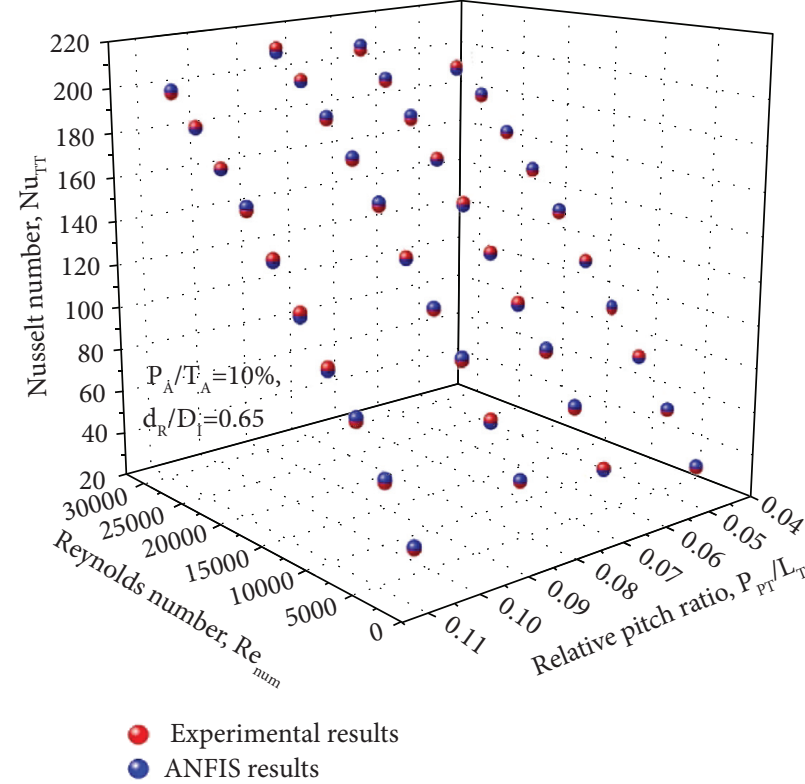

(a)

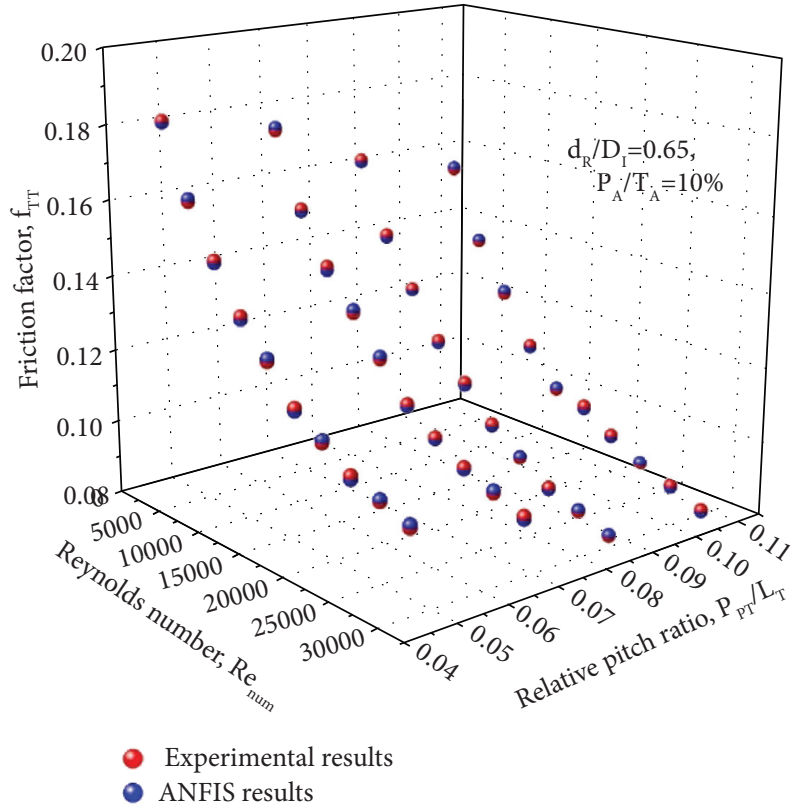

(b)

FIgURE 7: Experimental and ANFIS results of variation of (a) $N u_{T T}$ and (b) $f_{T T}$ for various values of $\left(P_{P T} / L_{T}\right)$ at different $\operatorname{Re} e_{\text {num }}$. 


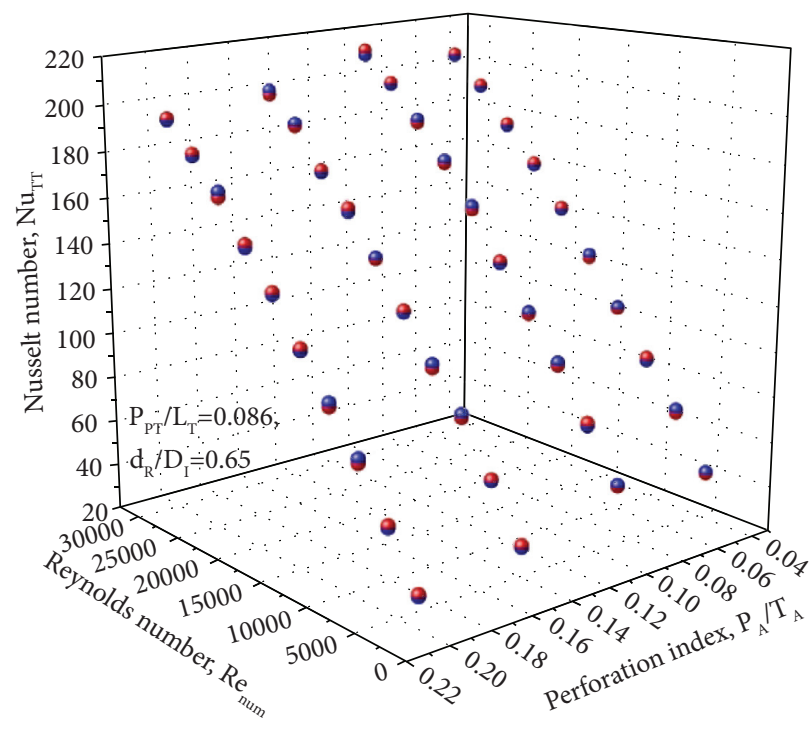

Experimental results

ANFIS results

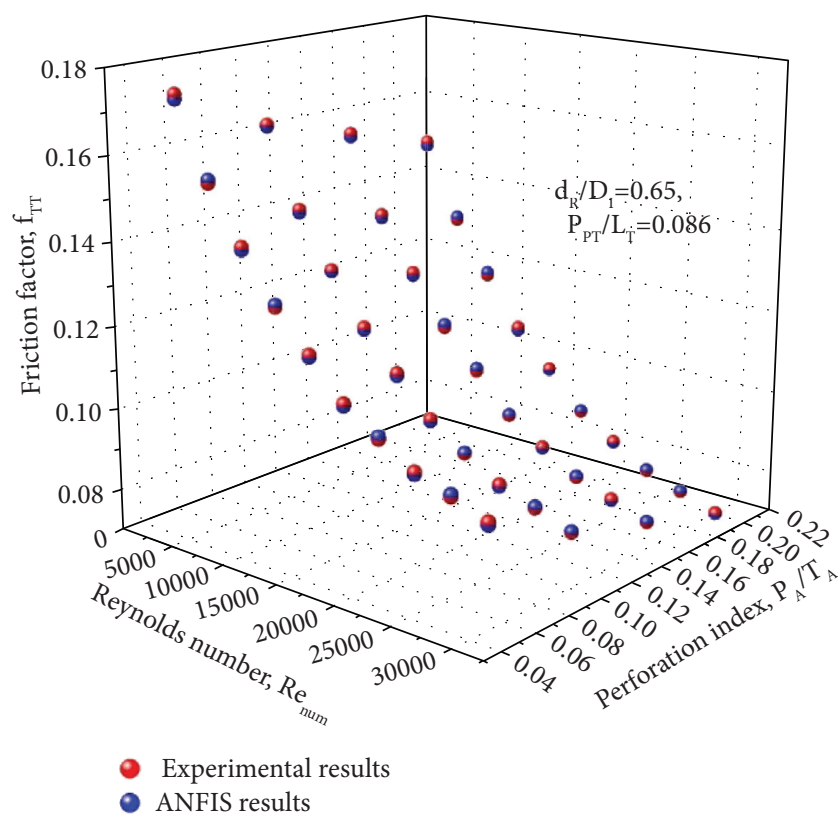

(b)

Figure 8: Experimental and ANFIS results of variation of (a) $N u_{T T}$ and (b) $f_{T T}$ for various values of $\left(P_{A} / T_{A}\right)$ at different $R e_{\text {num }}$.

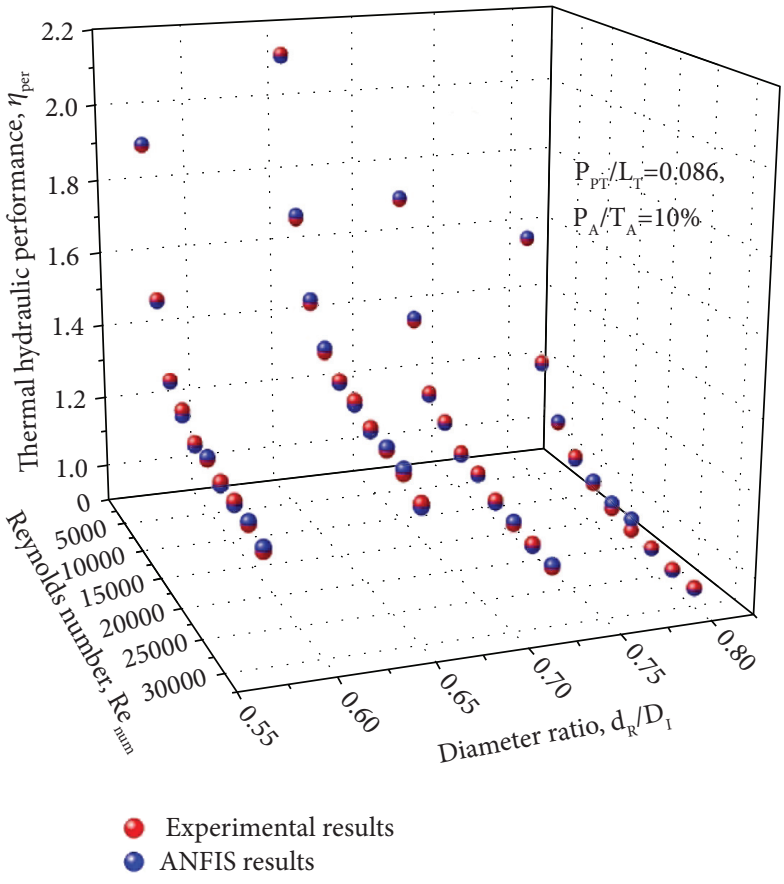

(a)

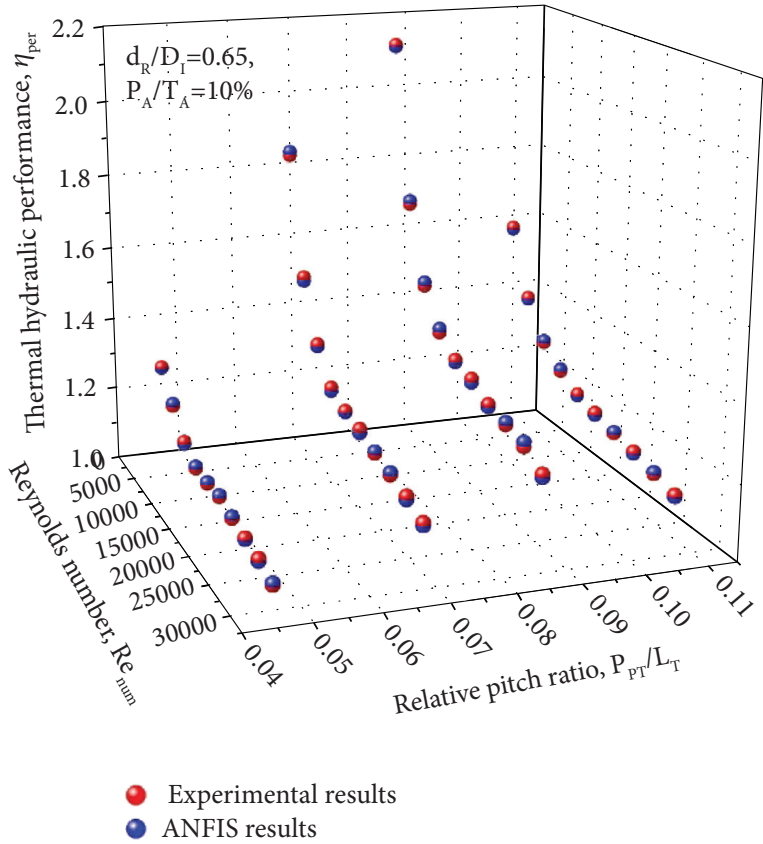

(b)

Figure 9: Continued. 


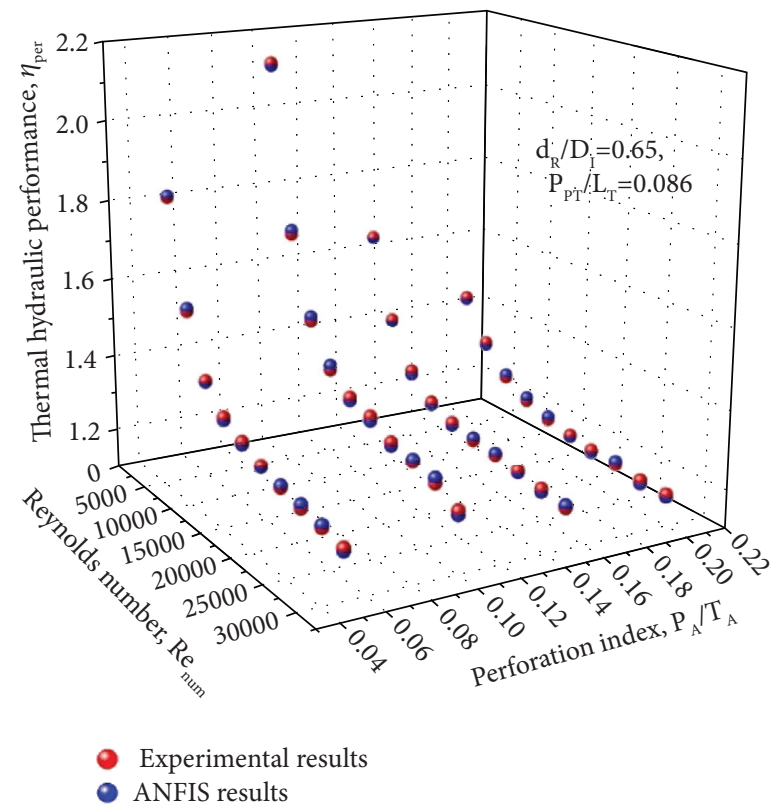

(c)

FiguRE 9: Experimental and ANFIS results of variation of $\eta_{\text {per }}$ for various values of $\left(d_{R} / D_{I}\right),\left(P_{P T} / L_{T}\right)$, and $\left(P_{A} / T_{A}\right)$ at different Re num.

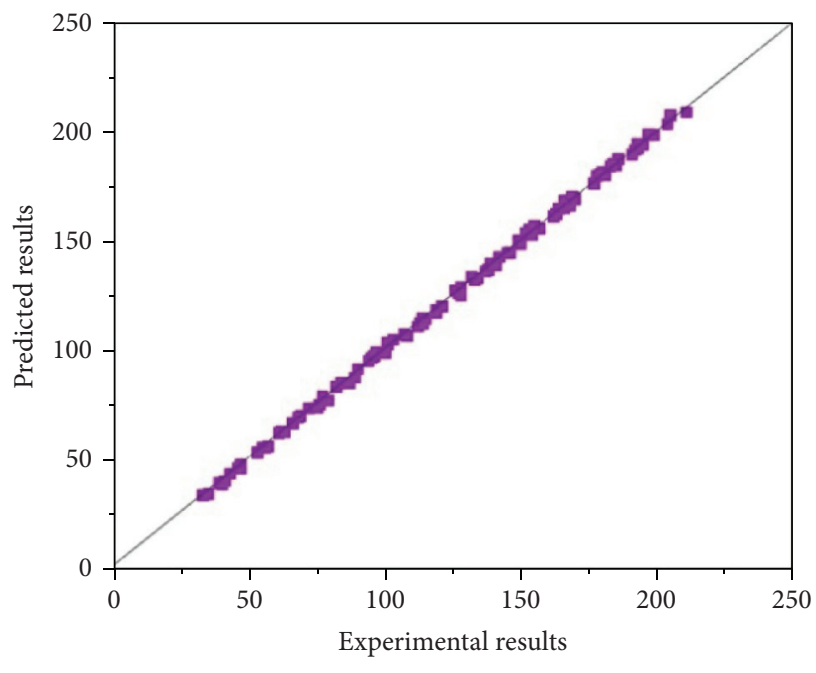

- Nusselt number

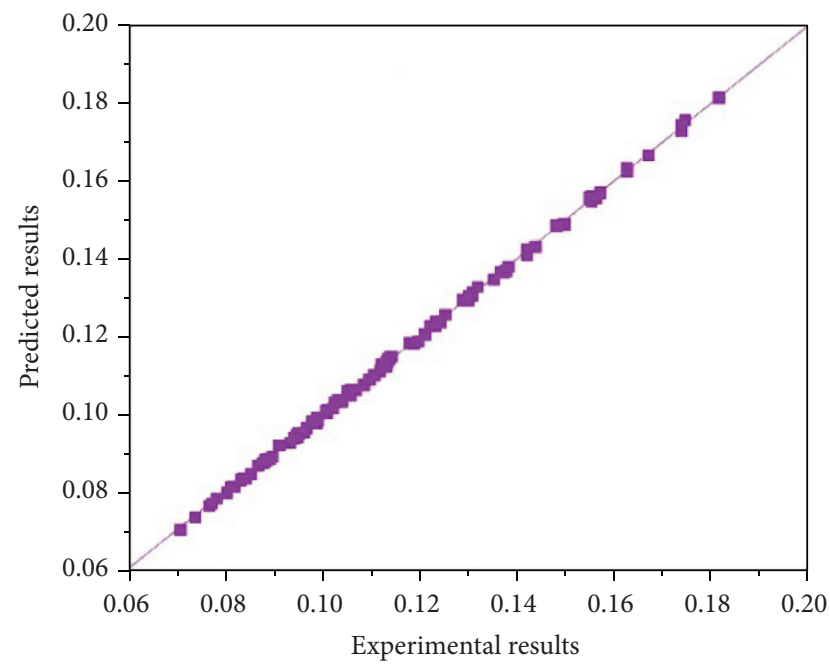

- Friction factor

(a)

(b)

FIGURE 10: Continued. 


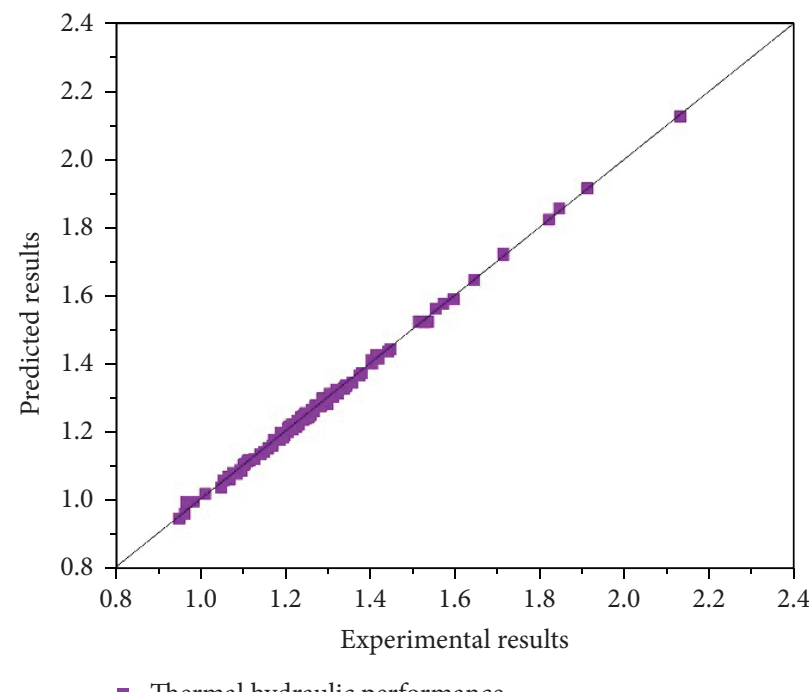

- Thermal hydraulic performance

(c)

FIGURE 10: Comparison of experimental vs predicted ANFIS results for (a) $N u_{T T}$, (b) $f_{T T}$, and (c) $\eta_{\text {per }}$.

\section{Conclusions}

This article deals with the analysis of the effect of flow and geometric parameters on the thermal performance of the heat exchanger tube fitted with a pierced twisted tape using the experimental and ANFIS models. The experimental and ANFIS models used four input parameters $\left(d_{R} / D_{I}\right)$, $\left(P_{P T} / L_{T}\right),\left(P_{A} / T_{A}\right)$, and $\mathrm{Re}_{\text {num }}$, and three output parameters $N u_{T T}, f_{T T}$, and $\eta_{\text {per }}$. The inferences drawn are as follows:

(1) The experimental and ANFIS results observed that the value of $N u_{T T}$ increases with an increase in $\left(d_{R} / D_{I}\right)$, and it attains the highest value at the $\left(d_{R} / D_{I}\right)$ value equal to 0.65 . Then, it starts decreasing with a further increase in the value of $\left(d_{R} / D_{I}\right)$. However, $f_{T T}$ continuously increases with an increase in the value of $\left(d_{R} / D_{I}\right)$.

(2) The experimental and ANFIS results showed that the value of increases $N u_{T T}$ with an increase in $\left(P_{P T} / L_{T}\right)\left(P_{P T} / L_{T}\right)$ and reaches to a higher value at the $\left(P_{P T} / L_{T}\right)$ value of 0.086 . With more rise in the value of $\left(P_{P T} / L_{T}\right)\left(P_{P T} / L_{T}\right), \quad N u_{T T}$ decreases. However, $f_{T T}$ increases with a decrease in the value of $\left(P_{P T} / L_{T}\right)\left(P_{P T} / L_{T}\right)$ and attains a higher value in relation to a $\left(P_{P T} / L_{T}\right)\left(P_{P T} / L_{T}\right)$ value of 0.046 .

(3) The experimental and ANFIS results showed that the value of $N u_{T T}$ increased with an increase in $\left(P_{A} / T_{A}\right)$ and attained the highest value corresponding to the $\left(P_{A} / T_{A}\right)$ value of $10 \%$. With a further increase in the value of $\left(P_{A} / T_{A}\right), N u_{T T}$ decreases. However, $f_{T T}$ increases with a decrease in the value of $\left(P_{A} / T_{A}\right)$ and reaches to an extreme value corresponding to the $\left(P_{A} / T_{A}\right)$ value of $5 \%$.

(4) The maximum thermal hydraulic performance was obtained with the $\left(d_{R} / D_{I}\right)$ value of 0.65 , the $\left(P_{P T} / L_{T}\right)\left(P_{P T} / L_{T}\right)$ value of 0.085 , and the $\left(P_{A} / T_{A}\right)$ value of $10 \%$. The prediction of the $N u_{T T} N u_{T T}, f_{T T}$, and $\eta_{\text {per }}$ with the ANFIS model agrees with the experimental investigation with a higher error of less than 0.53 .

(5) It is evident from the ANFIS and experimental results that the enhancement of heat transfer mainly depends on the type of geometrical parameters and the nature of fluid. Hence, in future, the ANFIS model can be used to predict the heat transfer and pressure drop of a nanofluid flow through twisted tape heat exchangers. Also, the Particle Swarm Optimization (PSO) algorithm can be employed to improve the ANFIS model for prediction.

\section{Nomenclature}

$A_{T}: \quad$ Area of test section, $m^{2}$

$D_{t}: \quad$ Diameter of tube, $\mathrm{m}$

$d_{R}: \quad$ Diameter of helical tape, $\mathrm{m}$

$\left(d_{R} / D_{I}\right):$ Diameter ratio

$h$ : $\quad$ Heat transfer coefficient, $\mathrm{W} / \mathrm{m}^{2} \cdot \mathrm{K}$

E: $\quad$ Energy, $J$

$f_{T T}: \quad$ Friction factor for twisted tape inserts

$f_{\text {smooth }}$ : Friction factor for smooth surface

$L_{t}: \quad$ Length of test section, $\mathrm{m}$

$\dot{m}$ : $\quad$ Mass flow rate, $\mathrm{kg} / \mathrm{s}$

$P_{P T}: \quad$ Pitch of helical pierced tape, $\mathrm{m}$

$\left(P_{P T} / L_{T}\right):$ Relative pitch ratio

$\left(P_{A} / T_{A}\right)$ : Perforation Index

$T_{A}: \quad$ Total area of helical tape, $\mathrm{m}^{2}$

$N u_{T T}: \quad$ Nusselt number for twisted tape inserts

$N u_{\text {smooth }}$ : Nusselt number for smooth surface

$p: \quad$ Pressure, $\mathrm{Pa}$

$\Delta p_{\text {ave }}: \quad$ Average pressure drops, $\mathrm{Pa}$

$Q_{u}: \quad$ Heat transfer rate, $\mathrm{W}$

$\mathrm{Re}_{\text {num }}$ : Reynolds number 


$$
\begin{array}{ll}
V: & \text { Mean velocity of fluid, } \mathrm{m} / \mathrm{s} \\
\eta_{\text {per }}: & \text { Thermohydraulic performance parameter. }
\end{array}
$$

\section{Data Availability}

The data used to support the findings of the study are included within the article.

\section{Conflicts of Interest}

The authors declare that there are no conflicts of interest regarding the publication of this article.

\section{Acknowledgments}

This study was funded by the University of Jeddah, Jeddah, Saudi Arabia.

\section{References}

[1] M. Mohanraj, S. Jayaraj, and C. Muraleedharan, "Applications of artificial neural networks for thermal analysis of heat exchangers-a review," International Journal of Thermal Sciences, vol. 90, pp. 150-172, 2015.

[2] A. Sivakumar, N. Alagumurthi, and T. Senthilvelan, "Experimental investigation of forced convective heat transfer performance in nanofluids of $\mathrm{Al} 2 \mathrm{O} 3 /$ water and $\mathrm{CuO} /$ water in a serpentine shaped micro channel heat sink," Heat and Mass Transfer, vol. 52, no. 7, pp. 1265-1274, 2015.

[3] S. Kumar, M. Shandilya, A. Chauhan, R. Maithani, and A. Kumar, "Experimental analysis of zinc oxide/water/ethylene glycol-based nanofluid in a square duct roughened with inclined ribs," Journal of Enhanced Heat Transfer, vol. 27, no. 8, pp. 687-709, 2020.

[4] M. H. Hamzah, N. A. C. Sidik, T. L. Ken, R. Mamat, and G. Najafi, "Factors affecting the performance of hybrid nanofluids: a comprehensive review," International Journal of Heat and Mass Transfer, vol. 115, pp. 630-646, 2017.

[5] A. Al-Rashed, "Optimization of heat transfer and pressure drop of nano-antifreeze using statistical method of response surface methodology," Physica A: Statistical Mechanics and its Applications, vol. 521, 2019.

[6] S. Kumar and A. Kumar, "A comprehensive review on the heat transfer and nanofluid flow characteristics in different shaped channels," International Journal of Ambient Energy, vol. 42 , no. 3, pp. $345-361,2021$.

[7] S. Kumar, R. Maithani, and A. Kumar, "Optimal design parameter selection for performance of alumina nano-material particles and turbulence promotors in heat exchanger: an AHP-TOPSIS technique," Materials Today: Proceedings, vol. 43, pp. 3152-3155, 2021.

[8] G. Huminic and A. Huminic, "Heat transfer and flow characteristics of conventional fluids and nanofluids in curved tubes: a review," Renewable and Sustainable Energy Reviews, vol. 58, pp. 1327-1347, 2016.

[9] M. E. Nakhchi and J. A. Esfahani, "Cu-water nanofluid flow and heat transfer in a heat exchanger tube equipped with cross-cut twisted tape," Powder Technology, vol. 339, pp. 985-994, 2018.

[10] Y. Xiaowen and W. L. Lee, "The use of helical heat exchanger for heat recovery domestic water-cooled air-conditioners," Energy Conversion and Management, vol. 50, no. 2, pp. 240-246, 2009.
[11] M. Ishak, T. A. Tahseen, and M. M. Rahman, "Experimental investigation on heat transfer and pressure drop characteristics of air flow over a staggered flat tube bank in crossflow," International Journal of Automotive and Mechanical Engineering, vol. 7, pp. 900-911, 2013.

[12] T. L. Fullerton and N. K. Anand, "Periodically fully-developed flow and heat transfer over flat and oval tubes using a control volume finite-element method," Numerical Heat Transfer, Part A: Applications, vol. 57, no. 9, pp. 642-665, 2010.

[13] J. Y. Jang and J. Y. Yang, "Experimental and 3-D numerical analysis of the thermal-hydraulic characteristics of elliptic finned-tube heat exchangers," Heat Transfer Engineering, vol. 19, no. 4, pp. 55-67, 1998.

[14] M. Zeeshan, S. Nath, and D. Bhanja, "Numerical study to predict optimal configuration of fin and tube compact heat exchanger with various tube shapes and spatial arrangements," Energy Conversion and Management, vol. 148, pp. 737-752, 2017.

[15] N. Benarji, C. Balaji, and S. P. Venkateshan, "Unsteady fluid flow and heat transfer over a bank of flat tubes," Heat and Mass Transfer, vol. 44, no. 4, pp. 445-461, 2007.

[16] T. A. Tahseen, M. Ishak, and M. M. Rahman, "An overview on thermal and fluid flow characteristics in a plain plate finned and un-finned tube banks heat exchanger," Renewable and Sustainable Energy Reviews, vol. 43, pp. 363-380, 2015.

[17] A. M. Hussein, "Adaptive neuro-fuzzy inference system of friction factor and heat transfer nanofluid turbulent flow in a heated tube," Case Studies in Thermal Engineering, vol. 8, pp. 94-104, 2016.

[18] H. Esen, M. Inalli, A. Sengur, and M. Esen, “Artificial neural networks and adaptive neuro-fuzzy assessments for groundcoupled heat pump system," Energy and Buildings, vol. 40, no. 6, pp. 1074-1083, 2008.

[19] T. A. Tahseen, M. Ishak, and M. M. Rahman, "Performance predictions of laminar heat transfer and pressure drop in an in-line flat tube bundle using an adaptive neuro-fuzzy inference system (ANFIS) model," International Communications in Heat and Mass Transfer, vol. 50, pp. 85-97, 2014.

[20] C. N. Huang and C. C. Yu, "Integration of taguchi's method and multiple-input, multiple-output ANFIS inverse model for the optimal design of a water-cooled condenser," Applied Thermal Engineering, vol. 98, pp. 605-609, 2016.

[21] F. Selimefendigil and H. F. Öztop, "Numerical analysis and ANFIS modeling for mixed convection of CNT-water nanofluid filled branching channel with an annulus and a rotating inner surface at the junction," International Journal of Heat and Mass Transfer, vol. 127, pp. 583-599, 2018.

[22] T. R. Kiran and S. P. S. Rajput, "An effectiveness model for an indirect evaporative cooling (IEC) system: comparison of artificial neural networks (ANN), adaptive neuro-fuzzy inference system (ANFIS) and fuzzy inference system (FIS) approach," Applied Soft Computing, vol. 11, no. 4, pp. 3525-3533, 2011.

[23] W. Suparta and A. A. Samah, "Rainfall prediction by using ANFIS times series technique in south tangerang, Indonesia," Geodesy and Geodynamics, vol. 11, no. 6, pp. 411-417, 2020.

[24] C. E. Onu, J. T. Nwabanne, P. E. Ohale, and C. O. Asadu, "Comparative analysis of RSM, ANN and ANFIS and the mechanistic modeling in eriochrome black-T dye adsorption using modified clay," South African Journal of Chemical Engineering, vol. 36, pp. 24-42, 2021.

[25] M. Mehrabi, S. M. Pesteei, and T. Pashaee, "Modeling of heat transfer and fluid flow characteristics of helicoidal doublepipe heat exchangers using adaptive neuro-fuzzy inference 
system (ANFIS)," International Communications in Heat and Mass Transfer, vol. 38, no. 4, pp. 525-532, 2011.

[26] H. Esen, M. Inalli, A. Sengur, and M. Esen, "Modelling a ground-coupled heat pump system using adaptive neurofuzzy inference systems," International Journal of Refrigeration, vol. 31, no. 1, pp. 65-74, 2008.

[27] R. Beigzadeh and M. Rahimi, "Prediction of thermal and fluid flow characteristics in helically coiled tubes using ANFIS and GA based correlations," International Communications in Heat and Mass Transfer, vol. 39, no. 10, pp. 1647-1653, 2012.

[28] R. Beigzadeh and M. Rahimi, "Prediction of heat transfer and flow characteristics in helically coiled tubes using artificial neural networks," International Communications in Heat and Mass Transfer, vol. 39, no. 8, pp. 1279-1285, 2012.

[29] H. Esen and M. Inalli, "ANN and ANFIS models for performance evaluation of a vertical ground source heat pump system," Expert Systems with Applications, vol. 37, no. 12, pp. 8134-8147, 2010.

[30] M. Hayati, A. Rezaei, and M. Seifi, "Prediction of the heat transfer rate of a single layer wire-on-tube type heat exchanger using ANFIS," International Journal of Refrigeration, vol. 32, no. 8, pp. 1914-1917, 2009.

[31] H. Esen, M. Inalli, A. Sengur, and M. Esen, "Predicting performance of a ground-source heat pump system using fuzzy weighted pre-processing-based ANFIS," Building and Environment, vol. 43, no. 12, pp. 2178-2187, 2008.

[32] S. Chen, J. Mao, F. Chen, P. Hou, and Y. Li, "Development of ANN model for depth prediction of vertical ground heat exchanger," International Journal of Heat and Mass Transfer, vol. 117, pp. 617-626, 2018.

[33] M. Hemmat Esfe, "Designing a neural network for predicting the heat transfer and pressure drop characteristics of Ag/water nanofluids in a heat exchanger," Applied Thermal Engineering, vol. 126, pp. 559-565, 2017.

[34] J. Gill and J. Singh, "Energetic and exergetic performance analysis of the vapor compression refrigeration system using adaptive neuro-fuzzy inference system approach," Experimental Thermal and Fluid Science, vol. 88, pp. 246-260, 2017.

[35] M. J. Zarei, F. Gholizadeh, S. Sabbaghi, and P. Keshavarz, "Estimation of $\mathrm{CO} 2$ mass transfer rate into various types of nanofluids in hollow fiber membrane and packed bed column using adaptive neuro-fuzzy inference system," International Communications in Heat and Mass Transfer, vol. 96, pp. 90-97, 2018.

[36] S. M. A. N. R. Abadi, M. Mehrabi, and J. P. Meyer, "Prediction and optimization of condensation heat transfer coefficients and pressure drops of R134a inside an inclined smooth tube," International Journal of Heat and Mass Transfer, vol. 124, pp. 953-966, 2018.

[37] K. C. Onyelowe, J. Shakeri, H. Salahudeen, A. B. Salahudeene, E. E. Arinze, and H. U. Ugwu, "Application of ANFIS hybrids to predict coefficients of curvature and uniformity of treated unsaturated lateritic soil for sustainable earthworks," Cleaner Materials, vol. 1, Article ID 100005, 2021.

[38] A. Marjani, M. Babanezhad, and S. Shirazian, "Application of adaptive network-based fuzzy inference system (ANFIS) in the numerical investigation of $\mathrm{Cu}$ /water nanofluid convective flow," Case Studies in Thermal Engineering, vol. 22, Article ID 100793, 2020.

[39] A. D. Saee, A. Baghban, F. Zarei, Z. Zhang, and S. Habibzadeh, "ANFIS based evolutionary concept for estimating nucleate pool boiling heat transfer of refrigerant-ester oil containing nanoparticles," International Journal of Refrigeration, vol. 96, pp. 38-49, 2018.
[40] H. Beiki, "Developing convective mass transfer of nanofluids in fully developed flow regimes in a circular tube: modeling using fuzzy inference system and ANFIS," International Journal of Heat and Mass Transfer, vol. 173, Article ID 121285, 2021.

[41] M. Bahiraei, S. Nazari, and H. Safarzadeh, "Modeling of energy efficiency for a solar still fitted with thermoelectric modules by ANFIS and PSO-enhanced neural network: a nanofluid application," Powder Technology, vol. 385, pp. 185-198, 2021.

[42] K. M. Yashawantha and A. V. Vinod, "ANFIS modelling of effective thermal conductivity of ethylene glycol and water nanofluids for low temperature heat transfer application," Thermal Science and Engineering Progress, vol. 24, Article ID 100936, 2021.

[43] S. Bahl, S. Singh, P. Goyal, and A. K. Bagha, "Experimental investigations on brass material and pin-fin based heat transfer system and its modeling by using adaptive neurofuzzy inference system," Materials Today: Proceedings, vol. 45, no. 6, pp. 5323-5327, 2021.

[44] S. Safarzadeh, M. Niknam-Azodi, A. Aldaghi, A. Taheri, M. Passandideh-Fard, and M. Mohammadi, "Energy and entropy generation analyses of a nanofluid-based helically coiled pipe under a constant magnetic field using smooth and micro-fin pipes: experimental study and prediction via ANFIS model," International Communications in Heat and Mass Transfer, vol. 126, Article ID 105405, 2021.

[45] M. Kaveh, R. A. Chayjan, I. Golpour, S. Poncet, F. Seirafi, and B. Khezri, "Evaluation of exergy performance and onion drying properties in a multi-stage semi-industrial continuous dryer: artificial neural networks (ANNs) and ANFIS models," Food and Bioproducts Processing, vol. 127, pp. 58-76, 2021.

[46] M. Vilela, G. Oluyemi, G. Oluyemi, and A. Petrovski, "A fuzzy inference system applied to value of information assessment for oil and gas industry," Decision Making: Applications in Management and Engineering, vol. 2, no. 2, pp. 1-18, 2019.

[47] H. Alolaiyan, H. A. Alshehri, M. H. Mateen, D. Pamucar, and M. Gulzar, "A novel algebraic structure of $(\alpha, \beta)$-complex fuzzy subgroups," Entropy, vol. 23, no. 8, p. 992, 2021.

[48] R. E. Precup, S. Preitl, E. Petriu et al., "Model-based fuzzy control results for networked control systems," Reports in Mechanical Engineering, vol. 1, no. 1, pp. 10-25, 2020.

[49] S. Thapa, S. Samir, K. Kumar, and S. Singh, "A review study on the active methods of heat transfer enhancement in heat exchangers using electroactive and magnetic materials," Materials Today: Proceedings, vol. 45, no. 6, pp. 4942-4947, 2021.

[50] R. Maithani and A. Kumar, "Effect of helical perforated twisted tape parameters on thermal and hydrodynamic performance in heat exchanger circular tube," Heat and Mass Transfer, vol. 56, no. 2, pp. 507-519, 2020.

[51] A. R. S. Suri, A. Kumar, and R. Maithani, "Heat transfer enhancement of heat exchanger tube with multiple square perforated twisted tape inserts: experimental investigation and correlation development," Chemical Engineering and Processing: Process Intensification, vol. 116, pp. 76-96, 2017. 